\title{
INTERPRETIVE SUMMARIES, APRIL 2010
}

Invited review: Ruminant ecology and evolution: Perspectives useful to ruminant livestock research and production. By Hackmann and Spain, page 1320. We review the phylogeny, evolutionary history, and ecological characteristics (distribution, abundance, body weight, dietary preferences) of wild ruminants. After a brief overview of ruminant domestication, we discuss several topics where ruminant ecology and evolution give insight to livestock systems, including (1) allometric equations, (2) physiological control of feed intake, (3) the primary function of the omasum, (4) mixed-species grazing systems, and (5) extended lactation.

Effect of somatic cell count in goat milk on yield, sensory quality, and fatty acid profile of semisoft cheese. By Chen et al., page 1345. Milk somatic cell count (SCC) is widely used as an indicator for both udder health and milk quality. An increased SCC may alter the protein fractions distribution and decrease casein and lactose levels in milk, therefore affecting the yield and quality of cheese. It is generally agreed that goat milk had higher SCC than cow milk. This study examined the effect of SCC of goat milk on milk and cheese quality. The results showed that milk composition of goats did not differ when milk SCC varied from 214,000 to $1,450,000$ cells $/ \mathrm{mL}$, but high $\mathrm{SCC}$ in milk resulted in lower sensory score in cheese.

Siderophore production and utilization by milk spoilage Pseudomonas species. By Brown and Luke, page 1355. Twenty Pseudomonas isolates with high milk spoilage ability were grown in iron-restricted media and the nature of siderophore production was examined. Pyoverdins were the most commonly produced siderophores, but some strains also produced other siderophores. Utilization of pyoverdins produced by other strains was found to be universal, but the number utilized differed among strains. Interference with the iron-uptake systems of Pseudomonas spp. may be a way in which food spoilage might be slowed. This work indicates that the pyoverdin system may be a worthwhile target.

Dietary cheese whey protein protects rats against mild dextran sulfate sodium-induced colitis: Role of mucin and microbiota. By Sprong et al., page 1364. Cheese whey protein is a rich source of the amino acids threonine and cysteine, which have been shown to protect laboratory animals from intestinal inflammation. The present study shows that cheese whey protein protected against clinical symptoms of intestinal inflammation in rats by enhancing the protective mucous layer that covers the intestinal tract and by stimulating the beneficial microbiota species lactobacilli and bifidobacteria. Therefore, cheese whey protein may be a useful ingredient for clinical foods for patients with inflammatory bowel disease.

Effect of different colored filters on photooxidation in pasteurized milk. By Intawiwat et al., page 1372. Light-induced oxidation reduces the quality of dairy products. Pasteurized milk contains various photosensitizers, which are degraded during light exposure. Fluorescence spectroscopy is a good technique to measure this degradation. In this experiment, milk was packed with transparent noncolored and colored filters with different optical transmission properties and exposed to light for $20 \mathrm{~h}$. Degradation of protoporphyrin and chlorophyllic compounds correlated well with sensory properties. Light-exposed milk covered with noncolored filters in air had a high level of lipid oxidation products and photosensitizers were severely degraded. In general, milk covered with red, green, and amber filters gave moderate off-flavor and off-odor scores and photosensitizers were slightly degraded.

Composition, coagulation properties, and cheesemaking potential of milk from cows undergoing extended lactations in a pasture-based dairying system. By Auldist et al., page 1401. Extending lactation beyond the traditional 10 mo of pasture-based dairying systems with seasonally concentrated calving patterns is an option for alleviating the difficulty of getting cows to conceive during peak lactation. We investigated the yield and quality of Cheddar cheese made from milk from cows undergoing extended lactations to ensure there were no detrimental effects. Milk from extended lactations had higher protein concentrations but similar ratios of different milk proteins and yielded more cheese of similar composition compared with milk from a traditional 10-mo lactation. Milk from extended lactations can therefore produce high quality cheese.

Effects of high hydrostatic pressure on the structure of bovine $\alpha$-lactalbumin. By RodilesLópez et al., page 1420. The effect of high hydrostatic pressure processing at 200 to $600 \mathrm{MPa}$ at 25 to $55^{\circ} \mathrm{C}$ for 5 to $15 \mathrm{~min}$ on the structure of the whey protein $\alpha$-lactalbumin was studied in the $\mathrm{pH}$ range of 3.0 to 9.0 . The various processes produced a variety of partially unfolded structures with good functional properties that showed higher stability to heat as the severity of the treatment increased. These enhanced structures can be used in more food processes than the original native structures.

Linear relationship between increasing amounts of extruded linseed in dairy cow diet and milk fatty acid composition and butter properties. 
By Hurtaud et al., page 1429. There is a wealth of research into the effects of polyunsaturated fatty acidrich oilseeds. This study reports the use of increasing amounts of extruded linseed. Milk fatty acid composition, especially $\alpha$-linolenic acid, is linearly improved by increasing amounts of extruded linseed. The effect on milk conjugated linoleic acid is relatively poor. Butter spreadability is linearly improved, but sensory properties are unchanged, except for the melts-in-the-mouth parameter. There is also no effect on butter color.

Importance of casein micelle size and milk composition for milk gelation. By Glantz et al., page 1444. The composition of milk is crucial for the processability and quality of milk-based products and thus the economic output to the dairy industry. It could therefore be an advantage if more traits on milk quality are considered in the breeding objectives. This study indicated that a selection for smaller native casein micelles and a lower milk $\mathrm{pH}$ through breeding would enhance gelation properties and may thus improve the initial step in the processing of cheese.

Management practices associated with conception rate and service rate of lactating Holstein cows in large, commercial dairy herds. By Schefers et al., page 1459. Data from Holstein dairy herds were analyzed using a machine learning algorithm to discover management factors associated with reproductive performance. The most important variables associated with conception rate were the percentage of repeated inseminations between 4 and $17 \mathrm{~d}$ post-artificial insemination, stocking density in the breeding pen, length of the voluntary waiting period, days at pregnancy examination, and somatic cell score. The most important variables associated with service rate were the number of lactating cows per breeding technician, use of a resynchronization program, use of soakers in the holding area during the summer, and bunk space per cow in the breeding pen.

Barium selenate supplementation and its effect on intramammary infection in pasture-based dairy cows. By Ceballos et al., page 1468. Selenium deficiency has been associated with lowered resistance to mastitis in dairy cattle. However, recommendations for supplementation of grazing herds are poorly defined. A long-acting Se supplement administered at drying off to pasture-based dairy cows in southern Chile resulted in a sustained increase of blood glutathione peroxidase activity. No changes were noted in the incidence of intramammary infections or somatic cell count during the subsequent lactation. These results suggest that the basal Se intake ( $\sim 1 \mathrm{mg}$ of Se/cow per day) of cattle grazing in southern Chile is adequate for preventing subclinical mastitis despite being $20 \%$ of the current National Research Council recommendation.
Mammary remodeling in primiparous and multiparous dairy goats during lactation. By Safayi et al., page 1478. In primiparous dairy goats, we found that mammary epithelial cell formation, mammary angiogenesis, and lactogenesis were delayed in the peripartum period compared with multiparous goats. Thus, mammary development continues further into lactation in primiparous goats. We provide evidence that the set of genes regulating the orchestrated changes in mammary epithelial cell and vascular function during lactation are also basically the same set of genes explaining different patterns of development between primi- and multiparous goats. Both vascular and mammary epithelial cell development are thus determinants of lactational performance and may be associated with the reported higher lactation persistency in primiparous goats.

Effect of bST (500 mg) administered at ten-day intervals on ovulatory responses, expression of estrus, and fertility in dairy cows. By Rivera et al., page 1500. Bovine somatotropin (bST) is administered at a dose of $500 \mathrm{mg}$ every $14 \mathrm{~d}$ to enhance lactation in dairy cows, but it has also been shown to improve fertility. When $500 \mathrm{mg}$ of bST was administered at 10-d intervals to dairy cows, yields of milk and milk components were improved but pregnancy per artificial insemination remained unaltered. Treatment with bST had minor effects on ovulatory responses, but reduced estrous behavior despite increased concentrations of estradiol. Treatment with bST at 10-d intervals improved lactation but it did not affect pregnancy per artificial insemination and reduced expression of estrus.

Determination of water quality variables, endotoxin concentration, and Enterobacteriaceae concentration and identification in southern High Plains dairy lagoons. By Purdy et al., page 1511. The objectives of this study were to compare southern High Plains dairy wastewater to the water of 2 control lakes and to determine whether certain dairy management practices were negatively affecting the environment and health and wellbeing of animals. The following water parameters were studied: endotoxin concentrations; 20 water quality variables; and concentrations and identification of bacterial, fungal, and yeast pathogens. Wastewater contained significantly more endotoxins and pathogens than did control lakes. Because of wastewater pollution, it was not considered prudent to abate dairy dust with wastewater. Also, forage crops must be adequately cured to prevent transmission of Salmonella spp. through irrigation water.

Associations between bovine coronavirus and bovine respiratory syncytial virus infections and animal performance in Swedish dairy herds. By Beaudeau et al., page 1523. The impact of bovine 
coronavirus virus and bovine respiratory syncytial virus infections in dairy herds was quantified in this study. Cows in bovine respiratory syncytial virus -infected herds had lower milk yield, higher SCC, and risk of failure after first service in comparison with those in free herds; the risk of death in young stock was also increased in these herds. Bovine coronavirus virus infection was not significantly associated with any production losses in animals from infected herds.

An improved method to culture Staphylococcus aureus from bovine milk. By Artursson et al., page 1534. In udder health programs aiming to control Staphylococcus aureus mastitis, identification of infected udder quarters is important. In this study, different methods for processing the milk samples in connection with bacterial culturing were tested. A simple modification of the processing resulted in the finding of $S$. aureus in $50 \%$ more udder quarter milk samples and $29 \%$ more cows with at least 1 positive milk sample than with the conventional method. The improved method will be especially useful when screening for $S$. aureus in herds with mastitis problems.

Nuclear magnetic resonance and mass spectrometry-based milk metabolomics in dairy cows during early and late lactation. By Klein et al., page 1539. Milk production in dairy cows has dramatically increased over the last decades. As a consequence, more energy is being allocated to milk synthesis and less to physiological processes essential to fertility and fitness. In this contribution, nuclear magnetic resonance spectroscopy and gas chromatographymass spectrometry have been applied to the determination of milk compounds during early and late lactation. Results revealed large differences for known biomarkers of energy metabolism during early lactation, indicating that individual animals cope very differentially with metabolic stress in this period.

Effects of clinical mastitis caused by grampositive and gram-negative bacteria and other organisms on the probability of conception in New York State Holstein dairy cows. By Hertl et al., page 1551. This study estimated the effects of gram-positive, gram-negative, and other clinical mastitis and additional factors on probability of conception in New York Holstein cows, using generalized linear mixed models. Conception probability decreased with each successive insemination. Clinical mastitis occurring any time between $14 \mathrm{~d}$ before until $35 \mathrm{~d}$ after an insemination was associated with a lower probability of conception. Its effect was greatest immediately before and after the time of insemination. In general, gramnegative mastitis was most detrimental. These findings should be helpful in management of mastitic cows before and after insemination.
Effects of sawdust bedding dry matter on lying behavior of dairy cows: A dose-dependent response. By Reich et al., page 1561. The stall surface can affect the amount of time cows spend lying down. In this study, cows were provided access to stalls that varied in the level of moisture in sawdust bedding during summer and winter conditions. Dairy cows spent less time lying down during summer and more time lying down when provided stalls with drier bedding. These results indicate that damp bedding reduces the lying behavior of dairy cows and that seasonal differences exist in lying time.

The use of a cephalonium containing dry cow therapy and an internal teat sealant, both alone and in combination. By Bradley et al., page 1566. The efficacy of a broad spectrum antibiotic or an internal teat sealant alone was compared with their use in combination. The use of the products in combination, in high somatic cell count infected cows at drying off resulted in a reduction in the incidence of infection at calving and of clinical mastitis in the subsequent lactation. Combination use in low somatic cell count uninfected cows at drying off resulted in a change in the pathogens causing infection and clinical mastitis rather than a reduction in the prevalence or incidence of infection.

Associations of soft flooring materials in free stalls with milk yield, clinical mastitis, teat lesions, and removal of dairy cows. By Ruud et al., page 1578. Associations between free-stall base softness and milk yield, incidence of clinical mastitis, teat lesions, and removal of cows were investigated. A questionnaire was sent to 1,923 dairy farms and 363 were included in the study. With the questionnaire, information regarding housing and stall base was obtained and was merged with production and disease data from the Norwegian Dairy Herd Recording System database. Farms were stratified into 5 groups according to softness of stall base. An increase in milk yield and a reduction in incidence of clinical mastitis, teat lesions, and removal of cows were found as stall base softness increased.

Factors influencing variation of bulk milk antibiotic residue occurrence, somatic cell count, and total bacterial count in dairy sheep flocks. By Gonzalo et al., page 1587. Antibiotic residue occurrence (ARO), somatic cell count (SCC), and total bacterial count (TBC) variables of bulk tank milk were studied over 5 yr in 209 dairy ewes flocks in CastillaLeón (Spain). High ARO were associated with high SCC, dry therapy practice, autumn season, and low milk yields. Low SCC and TBC were associated with continuously dry-treated flocks and machine milking. Continuously dry-treated flocks showed lower ARO 
than discontinuously treated flocks. The ARO, SCC, and TBC can be used to monitoring milk hygiene in dairy flocks throughout time.

Associations of elevated nonesterified fatty acids and $\beta$-hydroxybutyrate concentrations with early lactation reproductive performance and milk production in transition dairy cattle in the northeastern United States. By Ospina et al., page 1596. The associations between negative energy balance and both reproductive performance and milk production were evaluated with a cohort study of approximately 2,200 cows from 91 dairy herds in the northeastern United States. Energy balance was estimated with prepartum nonesterified fatty acids, postpartum $\beta$-hydroxybutyrate, and postpartum nonesterified fatty acids in 2 groups, those 14 to $2 \mathrm{~d}$ prepartum and those 3 to $14 \mathrm{~d}$ postpartum. Increased metabolite concentrations were associated with decreased reproductive performance and milk production in all groups except milk production in heifers sampled postpartum.

Changes in milk fatty acid profile and animal performance in response to fish oil supplementation, alone or in combination with sunflower oil, in dairy ewes. By Toral et al., page 1604. Dairy ewe diet was supplemented with sunflower oil, fish oil, or their combination with the aim of improving milk nutritional value and evaluating its effect on animal performance. Diets containing sunflower oil enhanced some health-promoting milk compounds, such as conjugated linoleic acid, more than fish oil alone, whereas the latter was more effective at improving milk n-3 fatty acids and reducing n-6:n-3 ratio. However, fish oil addition increased trans-C18:1, of which the harmlessness to humans has yet to be confirmed, and affected animal performance, reducing not only milk fat but also milk yield in the case of the combination of sunflower oil and fish oil.

The effects of Lactobacillus buchneri with or without a homolactic bacterium on the fermentation and aerobic stability of corn silages made at different locations. By Schmidt and Kung, page 1616. We studied the effects of Lactobacillus buchneri 40788 , combined with or without a homolactic bacterium, on the fermentation of corn silages from several locations. Overall, inoculation with L. buchneri, regardless of the presence or absence of Pediococcus pentosaceus, increased the concentration of acetic acid, reduced the populations of yeasts and molds, and improved the bunk life of the silages, although the response varied according to the locations. Thus, when L. buchneri is effective, it dominates the fermentation process and there is no antagonism from $P$. pentosaceus.
The effects of ruminally degraded protein on rumen fermentation and ammonia losses from manure in dairy cows. By Agle et al., page 1625. Livestock operations are the main source of ammonia emissions in the United States. Diet manipulation is one of the most effective methods for reducing ammonia losses from manure. This experiment investigated the effect of reducing dietary protein concentration and ruminal degradability on nitrogen excretion and ammonia emissions from manure in lactating dairy cows. Results demonstrate that reducing ruminally degraded protein intake reduced urinary nitrogen excretion and consequently the ammonia-emitting potential of dairy manure without affecting cow performance.

Successful control of Johne's disease in nine dairy herds: Results of a six-year field trial. $B y$ Collins et al., page 1638. Johne's disease was effectively controlled in 9 commercial dairy herds ranging in size from 68 to 1,413 cows. The control program used the recommended management changes for disease control together with a low cost diagnostic test, enzyme-linked immunosorbent assay (ELISA) for serum antibodies, applied to every cow once during each lactation. Only cows with strong-positive ELISA results were mandated for culling. Cows with low- or medium-level ELISA results were retained in the herd but managed to limit opportunities for infection transmission, demonstrating that within-herd prevalence of paratuberculosis can be significantly decreased by a low-cost control program.

Net flux of nutrients across splanchnic tissues of lactating dairy cows as influenced by dietary supplements of biotin and vitamin $\mathbf{B}_{12}$. By Girard and Desrochers, page 1644. Biotin and vitamin $\mathrm{B}_{12}$ are coenzymes essential to propionate metabolism in dairy cows. The objective of this study was to determine whether increasing dietary supply of these vitamins would change the supply of nutrients from the gastrointestinal tract and their utilization by the liver of lactating dairy cows. At the doses used, a dietary supplement of biotin $(20 \mathrm{mg} / \mathrm{d})$ and vitamin $\mathrm{B}_{12}$ (500 mg/d) altered ruminal fermentation as compared with unsupplemented cows. Supplementary vitamin $\mathrm{B}_{12}$ given alone increased release of glucose from the gastrointestinal tract and arterial concentration of glucose as compared with the 2 vitamins given together.

Milk fatty acid profile and dairy sheep performance in response to diet supplementation with sunflower oil plus incremental levels of marine algae. By Toral et al., page 1655. Dairy ewe diet was supplemented with 3 incremental levels of marine algae in combination with sunflower oil to evaluate the effects of these marine lipids on milk fatty acid profile 
and animal performance. The marine algae-sunflower oil diets remarkably enhanced some health-promoting milk compounds, such as conjugated linoleic acid, vaccenic acid, and n-3 fatty acid. On the other hand, marine algae addition induced milk fat depression and large increases in the content of trans-10 C18:1 in the milk, of which the specific role in relation to the risk of cardiovascular disease is still unknown.

Effect of feed delivery method on the behavior and growth of dairy heifers. By Greter et al., page 1668. The objective of this study was to determine the effects of feed delivery methods on growth, feeding competition, feeding, and sorting behavior of dairy heifers. Thirty-two Holstein heifers were exposed to 1 of 2 feed delivery treatments for $13 \mathrm{wk}$ : 1) total mixed ration or 2) top-dressed ration. Results demonstrated that feeding a total mixed ration to growing dairy heifers may promote a more even diurnal feeding pattern, minimize sorting and competitive behavior, and promote more solid fecal consistency.

Short communication: Responses to increasing amounts of free $\alpha$-linolenic acid infused into the duodenum of lactating dairy cows. By KhasErdene et al., page 167\%. Increasing the $\alpha$-linolenic acid content of milk fat might be desirable to meet consumer preference. The present study determined the potential to alter the content of $\alpha$-linolenic acid in milk by duodenal infusion of a free fatty acid mixture rich in $\alpha$-linolenic acid. Increasing the amount of $\alpha$-linolenic acid infused into the duodenum increased the concentrations of $\alpha$-linolenic acid and linoleic acid, and decreased de novo synthesized fatty acids, 18:1 cis9, and 18:2 cis-9,trans-11 in the milk.

Technical note: Determination of corn hardness in diverse corn germplasm using near-infrared reflectance baseline shift as a measure of grinding resistance. By Hoffman et al., page 1685. The baseline shift of near-infrared reflectance spectra, which is a result of grinding-induced particle size differentiation, was evaluated as an alternative measure of corn kernel hardness. Baseline shift was correlated with vitreousness, Stenvert grinding time, Stenvert column height, and ruminal dry matter degradability. Correlations were more robust for baseline shifts at shorter near-infrared wavelengths as compared with longer wavelengths or total near-infrared baseline shift $(1,000-$ $2,498 \mathrm{~nm})$. The partial baseline shift from 1,080 to $1,180 \mathrm{~nm}$ was better related to $14 \mathrm{~h}$ in situ ruminal dry matter degradability of corn germplasms than Stenvert grind time or column height.

Combining somatic cell count traits for optimal selection against mastitis. By Windig et al., page 1690. The aim of this study was to develop a more efficient index for breeding against mastitis by using somatic cell count (SCC). Genetic parameters of 10 traits derived from SCC test-day records, clinical mastitis (CM), and subclinical mastitis were used to calculate accuracy of different indices. An index with 5 SCC traits was selected because of its efficiency. It predicted a breeding goal of $50 \% \mathrm{CM}$ and $50 \%$ subclinical mastitis with an accuracy of 0.91 , whereas the current udder health index has an accuracy of 0.73. Adding direct information on CM improved the accuracy of the selected index only slightly.

Evaluation of five lactation curve models fitted for fat-protein ratio of milk and daily energy balance. By Buttchereit et al., page 1702. High-yielding dairy cows have to cope with a huge metabolic load. The resulting intensified energy deficit postpartum affects health and fertility. Because measurement of energy balance itself is costly, related traits such as the fat-protein ratio of milk could be useful selection criteria to improve metabolic stability. In this study, model evaluations for fat-protein ratio and daily energy balance were performed to establish a suitable model for further genetic analyses. In addition to testing the fit of several fixed and random regression models, the relationship between fat-protein ratio and energy balance was investigated.

Identification of single nucleotide polymorphisms in the bovine salute carrier family 11 member 1 (SLC11A1) gene and their association with infection by Mycobacterium avium subspecies paratuberculosis. By Ruiz-Larrañaga et al., page 1713. This study supports a role of the salute carrier family 11 member 1 gene in susceptibility to intracellular infection by Mycobacterium avium ssp. paratuberculosis in cattle. After a process of discovery and compilation of a significant part of the functional polymorphisms in this gene and a population-based genetic association study in European Holstein-Friesian animals, a marginally significant association has been observed between 2 single nucleotide polymorphisms and susceptibility to infection. The nonsynonymous single nucleotide polymorphism c.1067C $>$ G (P356A) has the greatest probability of being the hypothetical causative variant in this region, but additional work for confirmation is needed. The results of this study can be considered as the first step towards implementing a marker assisted selection method against paratuberculosis susceptibility in breeding programs.

Genetic parameters of milk ELISA scores for Johne's disease. By Attalla et al., page 1729. The heritability of the cow's ability to establish an immune response to Johne's disease (paratuberculosis) was computed based on antibody detection in Dairy Herd Improvement milk samples. Heritability estimates 
ranged from 0.065 to 0.095 , indicating that it is possible to compute genetic evaluations for resistance to Johne's disease. In the absence of genetic evaluations for Johne's resistance, genetic correlations indicated that the dairy industry's current practice of selecting for increased productive life and net merit should result in cows genetically more resistant to Johne's.

Effect of prolactin, $\beta$-lactoglobulin and $\kappa$-casein genotype on milk yield in East Friesian sheep. By Staiger et al., page 1736. The dairy sheep industry is a new but growing industry in North America. Marker assisted selection could play an important role in selection programs that target increased milk production. Three candidate genes were evaluated, but only the prolactin gene showed a strong association with milk production, indicating that this marker could potentially be used in marker assisted selection for increased milk yield in this East Friesian population.

Short communication: Heritability of milk fatty acid composition and stearoyl-CoA desaturase indices in dairy cows. By Garnsworthy et al., page 1743. Mammary stearoyl CoA desaturase (SCD) increases monounsaturated and decreases saturated fatty acid concentrations in milk. In a population of 2,408 cows, concentrations of individual fatty acids had low heritabilities, but SCD indices had heritabilities of up to 0.38 . This result indicates that indices of SCD activity could be used in selection programs to breed cows for improved milk fatty acid composition.

Short communication: Genetic variability in the predicted microRNA target sites of caprine casein genes. By Zidi et al., page 1749. MicroRNA are small nucleic acids that are able to bind at the $3^{\prime}$ untranslated region of a given messenger RNA and down-regulate the synthesis of the corresponding protein. Polymorphisms at microRNA target sites might be an important source of phenotypic variation in traits of economic interest. Herewith, we have identified five polymorphisms in the $3^{\prime}$ untranslated region of goat casein genes. In silico predictions have shown that these nucleotide substitutions map to putative microRNA target sites, suggesting that they might affect casein expression. These findings, once confirmed experimentally, would be relevant because changes in casein content strongly affect the processing properties of milk.

Short communication: Genetic trends of milk yield under heat stress for US Holsteins. $B y$ Aguilar et al., page 1754. Holstein test-day records for milk yield in 3 parities were analyzed by a multiple-trait random regression model that accounted for heat stress effects. The genetic trend for milk yield in absence of heat stress was positive for all parities. Genetic trends for the rate of decline under heat stress were flat in the first parity and negative in the later parities. The sensitivity to heat stress increases with the number of parities. Holsteins are currently selected against heat tolerance in later parities.

Trends in the Northeast dairy industry: Largescale modern confinement feeding and management-intensive grazing. By Winsten et al., page 1759. This paper provides a glimpse of the current structure of the dairy farm sector in the northeastern United States. In addition to descriptive farm and farmer characteristics, the paper provides information on farmer satisfaction levels and plans for the future of their farming operations. The trajectory for change in the Northeast continues to be toward fewer, larger, confinement-feeding dairy farms.

The effect of wide swathing on wilting times and nutritive value of alfalfa haylage. By Kung et al., page 1770. Wide swathing reduced the time alfalfa wilted in the field before it could be obtained safely for making silage. Wide-swathed alfalfa was harvested substantially earlier than narrow-swathed alfalfa when the targeted dry matter was between 43 to $45 \%$. Wideswathed alfalfa had higher concentrations of water soluble carbohydrates than did narrow-swathed alfalfa at ensiling, but this had minimal effects on silage fermentation. Wide swathing resulted in lower $\mathrm{N}$, higher acid detergent fiber, and a tendency for higher neutral detergent fiber than narrow swathing. Under the conditions of this study, wide swathing reduced drying times in the field but did not improve the nutritive value alfalfa silage.

Immigration policy, foreign agricultural labor, and exit intentions in the United States dairy industry. By Susanto et al., page 1774. This study analyzes the impact of hired foreign labor and herd sizes on United States dairy farmers' intentions to exit the industry. Based on a national survey of dairy farmers, it was found that exit intentions increase as the use of hired foreign labor increases, but intention to exit decreases rapidly as herd sizes get larger. The study also reveals that, given the current immigration policy in place, farmers who expect labor shortages in the future exhibit a greater tendency to exit the industry. 